\title{
Autoimmune Diseases Involving Multiple Organ Systems with Special References to SLE*
}

\author{
Masaichi Fukase, M D \\ Department of Internal Medicine, Part II, Faculty of Medicine Kyoto University
}

This article describes an evaluation of the preliminary criteria for classification of SLE proposed by American Rheumatism Association (ARA criteria for SLE), epidemiology of SLE in Japan and studies on several items such as heredity, predisposition, qualitative and quantitative abnormalities of lymphocytes and autoimmunity which are considered to have some relationship to etiology and/or pathogenesis of autoimmune diseases involving multiple organ systems.

ARA criteria for SLE were applied to patients with SLE (including early cases), rheumatoid arthritis (RA), progressive systemic sclerosis (PSS), dermatomyositis, periarteritis nodosa, chronic nephritis, and malignant lymphoma presented by physicians and dermatologists of SLE Reseatch Committee. Sensitivity of the criteria for SLE was $84 \%$, and specificities against RA, PSS and others were $87 \%$, $73 \%$ and $82 \%$ respectively.

For the purpose of study on epidemiology of SLE, the task force of Japanese Health and Welfare Ministry (the chief of SLE Research Committee of the task force, Prof. Dr. M. Fukase) sent questionnaires about the number of out- and inpatients with SLE for a year in 1972 and about their related detailed data to hospitals with more than 20 beds all over Japan (except Okinawa). From the data,

\footnotetext{
* Presented at the 72 nd Annual Meeting of the Japanese Society of Internal Medicine, April 4, 1975, in Kyoto.
}

the number of patients with SLE was estimated statistically from 6,300 to 8,500 in Japan. The prevalence of SLE was about 50 per million of population. There was no relationship between prevalence of patients with SLE and the latitude and weather in 46 districts in Japan. It is, however, interesting to point out that prevalence of such other autoimmune diseases as multiple sclerosis, myasthenia gravis, Behçet disease and sarcoidosis as well as SLE were highly observed in Tokyo district and lshikawa prefecture, though the reason is unknown. One thousand one hundred and eighty nine cases $(49.8 \%)$ among 2,451 patients with SLE diagnosed at each hospital and having detail informations met the ARA criteria which are termed the definite cases.

The family occurrence of SLE was observed in $3.6 \%$ of the total definite cases, which is much higher than that in the general population. The kinships of familial SLE patients to probands are shown in the first figure. Seven sets of identical twins (including one probable case) collected from Japanese literatures were presented, of which both or one have been affected by SLE; four sets of them were concordances, two questionable concordances and one was a discordance as shown in the first table. The age distribution of patients with the definite SLE and discoid lupus showed the peak in the 3rd decade, and in the fifth decade 


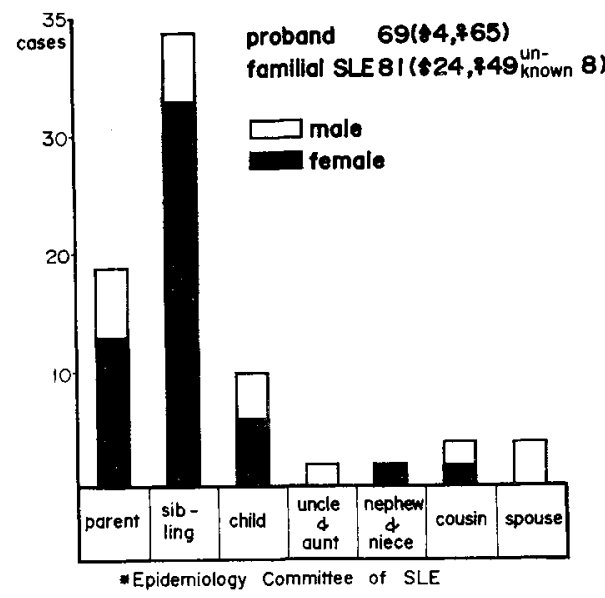

Fig. 1. Kinship of familial SLE to probands

\begin{tabular}{|c|c|c|c|c|c|c|}
\hline \multirow{5}{*}{ 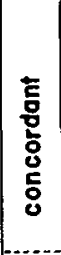 } & $\begin{array}{c}\text { relotionship } \\
\text { of } \\
\text { twins } \\
\end{array}$ & $\begin{array}{l}\text { age } \\
\text { sex }\end{array}$ & $\begin{array}{l}\text { age } \\
\text { on } \\
\text { onset }\end{array}$ & diagnosis & HLA & reposer \\
\hline & identical & $28, F$ & \begin{tabular}{|l|}
18 \\
18 \\
\end{tabular} & $\begin{array}{l}\text { SLE.Pomiculiti } \\
\text { SLE.ponniculitic }\end{array}$ & & \begin{tabular}{|l|} 
Tokyouniv. \\
Tsuruet al
\end{tabular} \\
\hline & identical & 22.5 & $\begin{array}{l}19 \\
19 \\
\end{array}$ & \begin{tabular}{|l|} 
SLE \\
SLE \\
\end{tabular} & & $\begin{array}{l}\text { FukuiRed Cross } \\
\text { Tsuboi of al } \\
\end{array}$ \\
\hline & identical & $46, F$ & & $\begin{array}{l}\text { SLE } \\
S L E\end{array}$ & & \begin{tabular}{|l|} 
Aichi Soizoikai \\
Mizuno
\end{tabular} \\
\hline & not stated. & $16, F$ & $\begin{array}{r}3 \\
16 \\
\end{array}$ & \begin{tabular}{|l|} 
SLE \\
SLE \\
\end{tabular} & & $\begin{array}{l}\text { KanazawaUhiv. } \\
\text { Seno of at }\end{array}$ \\
\hline \multirow[b]{2}{*}{$\sim$} & identical & $34, F$ & $\begin{array}{l}26 \\
34\end{array}$ & SLE, chumproiditis & $2,->140$, & $\begin{array}{l}\text { Kyoto Univ. } \\
\text { Tsunematsu }\end{array}$ \\
\hline & identical & $15, F$ & $\begin{array}{l}12 \\
15 \\
\end{array}$ & SLE & $2 ;-/ \mathrm{H}_{22}=$ & \begin{tabular}{|l|} 
Tokyo Univ. \\
Nakanoetal \\
\end{tabular} \\
\hline 总兽 & identical & $2 \mathrm{l}, \mathrm{F}$ & 14 & $\begin{array}{l}\text { SLE } \\
\text { healthy }\end{array}$ & $\mid$ & $\begin{array}{l}\text { Koio Univ. } \\
\text { Tominoga of af }\end{array}$ \\
\hline
\end{tabular}

Table 1. SLE of twins

respectively. The ratio of female to male in definite cases was 11 .

The clinical manifestations and laboratory findings are shown in the second and third figure. When the incidences of manifestations of Japanese cases listed up in the ARA criteria are compared with those of Americans, Englishes and Canadians, facial erythema, Raynaud's phenomenon and hematological abnormalities are observed more frequently and pleurisy and pericarditis less frequently. Twelve percent of definite cases died, and $74 \%$ of them ameriorated in a year. In respect to treatment of the acute bout of SLE with synthetic corticosteroids, the usage of corticosteroids equivalent to more than $50 \mathrm{mg}$ prednisone per day at a maximum gave statistically a better result in remission and amerio-

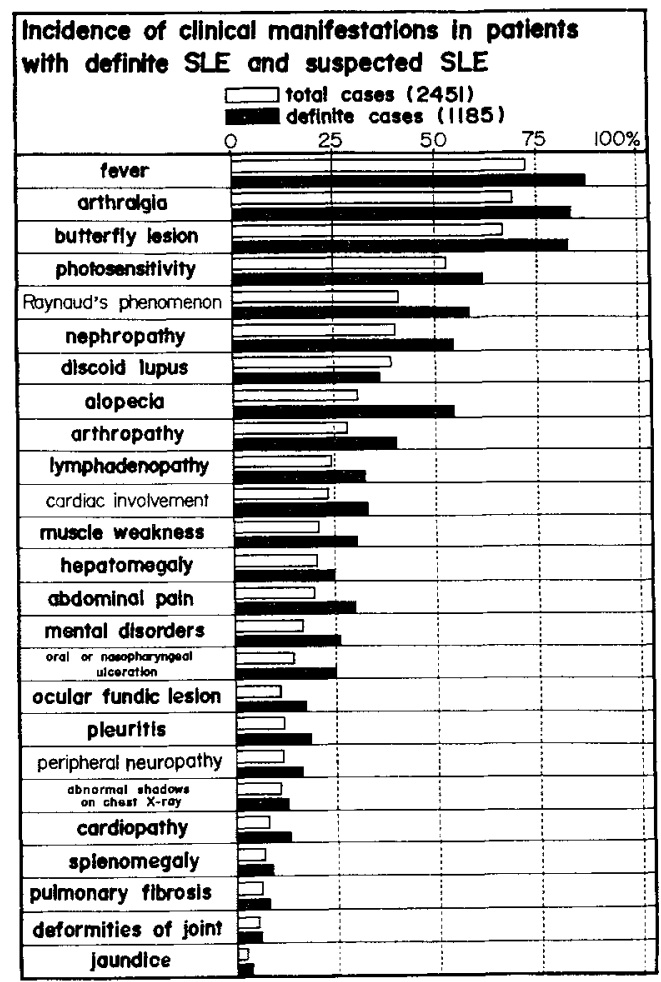

Fig. 2

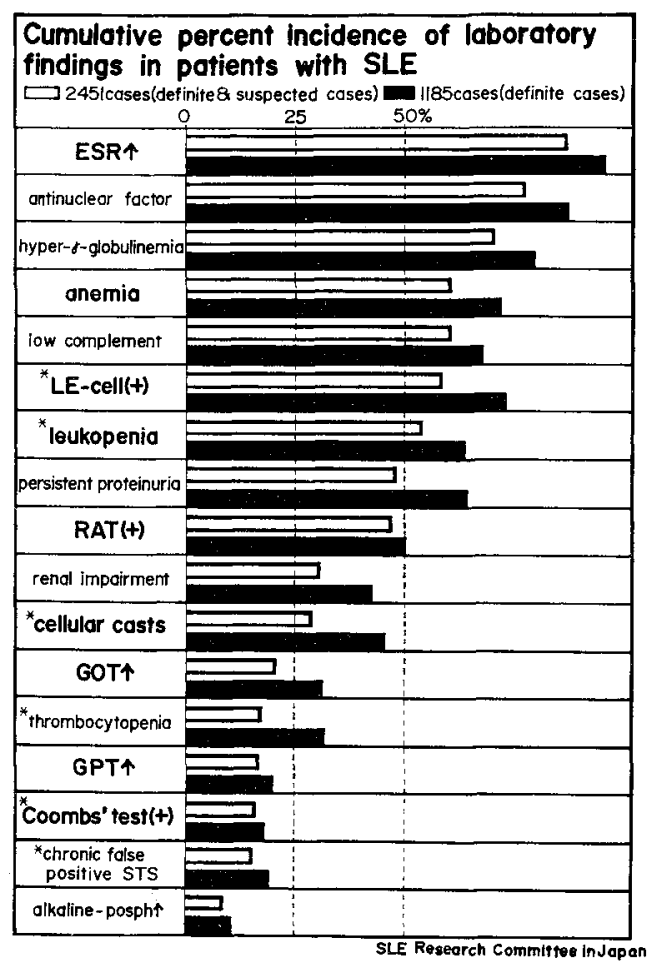

Fig. 3

Jap J Med Vol 15, No 1 (Jan 1976) 
ration of renal function than that of less than $50 \mathrm{mg}$ in a half year of follow-up period. With regard to treatment of renal failure in patients with SLE, on which corticosteroid administration had been ineffective, the hemodialys is therapy gave a good result in more than 3 months survival of 11 out of 15 patients.

In terms of quantitative and morphological abnormalities of lymphocytes in peripheral blood from patients with various autoimmune diseases, a significant decrease in $T$-cell count from patients with SLE, PSS and RA, and remarkable aberration of number and shape and enlargement of interband of chromosomes at the stage of metaphase of lymphocytes in patients with SLE cultured with PHA, were demonstrated. In terms of functional aberration of the lymphocytes in immunology, the significant decrease in blastogenesis, cytotoxic activity and IgG production in SLE and PSS, which are induced by PHA, were demonstrated. An inhibition of PHA induced blastogenesis of lymphocytes by human chorionic gonadotropin was demonstrated weaker in patients with SLE than in normal persons. Fig. 4 shows the PHA-induced cytotoxicity of lympho. cytes in various autoimmune diseases. The leukocyte migration inhibition tests were performed on lymphocytes from patients with SLE, PSS, and RA to detect the existence of cell-mediated immunities

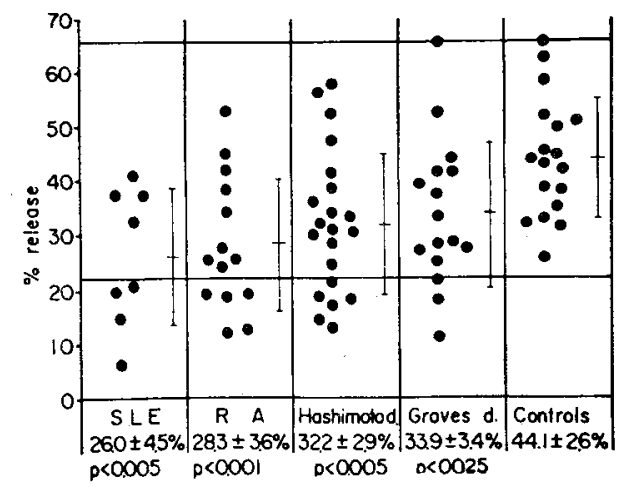

Fig. 4. PHA-induced cytotoxicity in patients with various autoimmune diseases

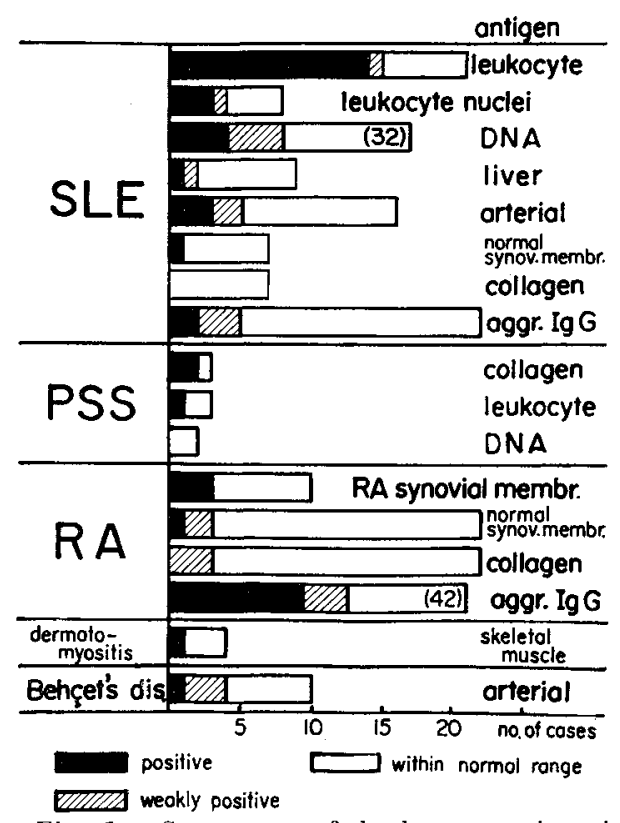

Fig. 5. Summary of leukocyte migration test in various systemic autoimmnne and its related diseases

to organ specific and organ non-speciffc antigens (see Fig. 5). The results from the tests are shown in Fig. 5.

The patterns of HL-A antigens of lymphocytes from patients with various autoimmune and its related diseases were defined in order to detect a certain relationship between constitutional predisposition to the diseases and HL-A antigens. The results are shown in table 2. HL-A 8 in the SLE and lupoid hepatitis,

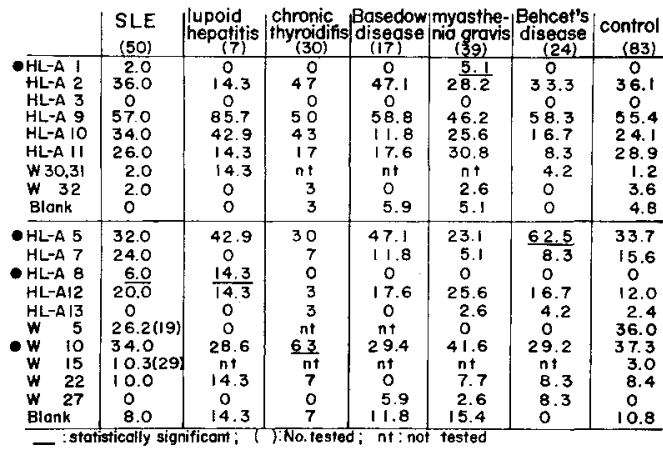

Table 2. Positive frequency of $\mathrm{HL}-\mathrm{A}$ antigens and autoimmune diseases 
W10 in the Hashimoto's thyroiditis, and $\mathrm{HL}-\mathrm{Al}$ in the myasthenia gravis were observed with significantly higher frequency than in the control. As for humoral autoantibodies, anti-luteinizing hormone-antibodies were described in patients with SLE which has probably not been reported yet, besides the reports of the incidence of many kinds of antibodies to such various organ specific and non-specific antigens as thyroglobulin, red cell, leukocyte, muscle, nuclei, microsome, mitochondria, $\operatorname{IgG}$, DNA and of LE-cell phenomenon and biological falsepositive reaction for syphilis. It was demonstrated that there was a certain connection between the titers of antiDNA antibodies among these antibodies or an amount of DNA-anti-DNA-antibody immune-complex and the activity of SLE or grade of renal injury in SLE. 